\title{
Espécies e sorovares de Listeria isolados de animais doentes e portadores no Brasil $^{1}$
}

\author{
Ernesto Hofer ${ }^{2 *}$ e Cristhiane Moura Falavina dos Reis ${ }^{2}$
}

\begin{abstract}
Hofer E. \& Reis C.M.F. 2005. [Species and serovars of Listeria isolated from sick and clinically healthy animals in Brazil.] Espécies e sorovares de Listeria isolados de animais doentes e portadores no Brasil. Pesquisa Veterinária Brasileira 25(2):79-83. Laboratório de Zoonoses Bacterianas, Depto Bacteriologia, Instituto Oswaldo Cruz/FIOCRUZ, Rio de Janeiro, RJ 21045-900, Brazil.E-mail: ehofer@ioc.fiocruz.br

Two hundred fourty-six strains of the genus Listeria were isolated from sick and clinically healthy animals, collected in three different regions of Brazil during 1971-2000. About 88.2\% (217 cultures) yielded Listeria species from faecal specimens of healthy cattle and 29 strains (11.7\%) were isolated from sick animals: $15(6.0 \%)$ from central nervous system (CNS) and 14(5.6\%) were from otherwise sterile sites. Phenotyping techniques were used to characterize the Listeria isolates. The commonest were $L$. innocua $6 \mathrm{a}$ and non-typable (140/56.9\%), L. monocytogenes $4 \mathrm{a}(37 / 15.0 \%)$ and $4 \mathrm{~b}$ $(22 / 8.9 \%)$, originated mainly from stools of healthy cattle. From sick animals the predominant species and serovars were $L$. monocytogenes $4 \mathrm{~b}(14 / 5.6 \%)$, and the higher incidence was observed in ruminants (12/4.8\%) and 8/3.2\% of the serovar 1 a from other animal species (rodents and canines) mainly isolated from CNS samples.
\end{abstract}

INDEX TERMS: Listeria, species, serovars, sick and healthy animals.

RESUMO.- A análise fenotípica de 246 amostras do gênero Listeria isolados de animais portadores e doentes, provenientes de três regiões do país, colecionadas no período de 1971 a 2000 , permitiu caracterizar as espécies e sorovares prevalentes. Dentre os animais predominaram os espécimes fecais de bovinos normais (217 amostras, 88,2\%), em contraposição aos 29 isolados $(11,7 \%)$ de Listeria de animais doentes, apresentando comprometimento do sistema nervoso central (15 amostras, 6,0\%) e outras localizações sistêmicas (14 amostras, 5,6\%). Quanto às espécies e sorovares, predominaram $L$. innocua 6a e não tipável (140 amsotras, 56,9\%) e L.monocytogenes 4a (37 amostras, 15,0) e 4b (22 amostras, $8,9 \%$ ) principalmente nas fezes de bovinos hígidos e nos animais doentes, $L$. monocytogenes sorovares $4 \mathrm{~b}$ (14 amostras, 5,6\%) com destaque nos ruminantes e 1a (8 amostras, $3,2 \%$ ) incidindo nas outras espécies animais (roedores e canídeos) e tendo localizações prevalentes em áreas distintas ao sistema nervoso central.

TERMOS DE INDEXAÇÃO: Listeria, espécies, sorovares, animais doentes e portadores.

\footnotetext{
${ }^{1}$ Recebido em 13 de novembro de 2003.

Aceito para publicação em 23 de maio de 2004

2 Depto Bacteriologia, Instituto Oswaldo Cruz/FIOCRUZ, Av. Brasil 4365, Manguinhos, Rio de Janeiro, RJ 21045-900. *Autor para correspondência. E-mail: ehofer@ioc.fiocruz.br
}

\section{INTRODUÇÃO}

A primeira observação sobre Listeria em animais provavelmente coube a Hülphers em 1911 (apud Seeliger 1961), que isolou de focos necróticos em fígado de coelho uma bactéria, denominada de Bacillus hepatis. Em 1926, durante uma epizootia em animais de laboratório (coelhos e cobaias) do biotério da Universidade de Cambridge, Murray et al. descrevem o agente como Bacterium monocytogenes. No ano seguinte, Pirie (1927) estudando uma epizootia em roedores na África do Sul, isolou de fígado uma bactéria que recebeu a denominação de Listerella hepatolytica, em homenagem a lorde Joseph Lister. Finalmente, em 1940, o microrganismo foi caracterizado de forma definitiva como Listeria monocytogenes (Pirie 1940), sendo progressivamente relatado em mais de 42 espécies de mamíferos (incluindo o homem) e 17 espécies de aves, além de ser reconhecida em peixes, crustáceos, ácaros e insetos (Seeliger 1961, Gray \& Killinger 1966).

Do ponto de vista ecológico as espécies de Listeria foram isoladas do solo, poeira, água, esgoto, vegetais e silagem (Gray \& Killinger 1966, Welshimer 1968, Weis 1975, Hofer 1974, 1975a,b, Watkins \& Sleath 1981, Hofer \& Povoa 1984). Na atualidade, os representantes patogênicos do gênero Listeria adquiriram uma extraordinária importância através da veiculação por alimentos (Farber \& Peterkin 1991, Hofer 2001).

Considerando as discretas referências sobre o binômio Listeria-listeriose nos animais em nosso meio, procurou-se nesta 
investigação fazer uma abordagem retrospectiva quanto às espécies e sorovares ocorrentes neste acontecimento nos três últimos decênios.

\section{MATERIAL E MÉTODOS}

Foram analisadas 246 amostras de Listeria, isoladas e/ou recebidas no período de 1971 a 2000 , mantidas sob a forma de coleção em tubos contendo meio semi-sólido em camada alta (caldo tryptose com $0,4 \mathrm{~g} \%$ de agar - Difco), vedados com rolhas de cortiça parafinadas e/ou de borracha. As culturas foram conservadas à temperatura de 4$8^{\circ} \mathrm{C}$.

As amostras foram isoladas de diferentes espécies animais e provenientes de alguns estados brasileiros (Quadro 1), mas com predominância de isolamentos do próprio laboratório (Hofer 1983) e outras encaminhadas por entidades universitárias e de pesquisa, visando obter um diagnóstico laboratorial conclusivo.

Identificação fenotípica dos isolados foi realizada com base nas características morfotintoriais, através da bacterioscopia pelo método de Gram e pelo perfil bioquímico, segundo Rocourt et al. (1983), incluindo-se rotineiramente a pesquisa da catalase e o comportamento hemolítico no teste de CAMP com Staphylococcus aureus e Rhodococcus equi.

A determinação antigênica dos sorogrupos e sorovares foi efetuada adotando-se a orientação de Seeliger \& Höhne (1979), utilizando-se antissoros somáticos e flagelares policlonais, elaborados pelo Laboratório de Zoonoses Bacterianas, Instituto Oswaldo Cruz/ FIOCRUZ, RJ.

\section{RESULTADOS}

No período de 1971 a 2000 foram analisadas 284 culturas com diagnóstico presuntivo, ou mesmo conclusivo de Listeria, nas quais, 246 se compatibilizaram fenotipicamente no gênero, representando portanto, $86,6 \%$ de acertos. As 38 cepas negativas foram excluídas pelos resultados da bacterioscopia (predominância de cocos Gram-positivos), pela ausência de mobilidade à temperatura ambiente e não produção da catalase. Excepcionalmente, foram reconhecidas bactérias Gram-negativas (Proteus spp e Pseudomonas spp) e bacilos Gram-positivos (Bacillus spp).

Quadro 1. Frequiência de membros do gênero Listeria isolados de diferentes espécies animais no período de $1971-2000$ e distribuídos segundo a origem geográfica

\begin{tabular}{|c|c|c|c|c|c|}
\hline \multirow{2}{*}{$\begin{array}{l}\text { Espécies } \\
\text { animais }\end{array}$} & \multicolumn{3}{|c|}{ Origem } & \multicolumn{2}{|c|}{ Total } \\
\hline & Rio de Janeiro & Rio Grande do Sul & Pernambuco & № & $\%$ \\
\hline \multicolumn{6}{|l|}{ Bovinos } \\
\hline adultos, portadores & 217 & - & - & 217 & 88,2 \\
\hline doentes & 8 & 2 & - & 10 & 4,0 \\
\hline fetos & - & 4 & - & 4 & 1,6 \\
\hline Roedores & $1^{\mathrm{a}}$ & $6^{\mathrm{b}}$ & - & 7 & 2,8 \\
\hline Caprinos & - & - & 3 & 3 & 1,2 \\
\hline Ovinos & 3 & - & - & 3 & 1,2 \\
\hline Caninos & 2 & - & - & 2 & 0,8 \\
\hline Total & $231(93,9)$ & $12(4,8)$ & $3(1,2)$ & 246 & 99,9 \\
\hline
\end{tabular}

Quadro 2. Distribuição de espécies e sorovares de Listeria segundo a origem geográfica

\begin{tabular}{|c|c|c|c|c|c|}
\hline \multirow{2}{*}{$\begin{array}{l}\text { Espécies/ } \\
\text { sorovares }\end{array}$} & \multicolumn{3}{|c|}{ Origem } & \multicolumn{2}{|c|}{ Total } \\
\hline & Rio de Janeiro & Rio Grande do Sul & Pernambuco & № & $\%$ \\
\hline \multicolumn{6}{|c|}{ L. monocytogenes } \\
\hline $1 \mathrm{a}$ & 3 & 6 & - & 9 & 3,7 \\
\hline $1 \mathrm{~b}$ & 10 & 2 & - & 12 & 4,8 \\
\hline $3 a$ & 1 & - & - & 1 & 0,4 \\
\hline $4 a$ & 37 & - & - & 37 & 15,0 \\
\hline $4 \mathrm{ab}$ & 5 & - & - & 5 & 2,0 \\
\hline $4 \mathrm{~b}$ & 31 & 2 & 3 & 36 & 14,6 \\
\hline $4 \mathrm{e}$ & 1 & 1 & - & 2 & 0,8 \\
\hline \multicolumn{6}{|l|}{ L. innocua } \\
\hline $6 a$ & 97 & 1 & - & 98 & 39,8 \\
\hline $\mathrm{Nt}^{*}$ & 44 & - & - & 44 & 17,8 \\
\hline \multicolumn{6}{|l|}{ L. ivanovii } \\
\hline 5 & 1 & - & - & 1 & 0,4 \\
\hline L. grayi & 1 & - & - & 1 & 0,4 \\
\hline Total & $231(93,9 \%)$ & $12(4,8 \%)$ & $3(1,2 \%)$ & 246 & 99,9 \\
\hline
\end{tabular}


Quadro 3. Distribuição das espécies e sorovares de Listeria de acordo com as fontes de infecção e de isolamento

\begin{tabular}{|c|c|c|c|c|c|c|c|c|c|c|c|c|c|}
\hline \multirow{2}{*}{$\begin{array}{l}\text { Fontes de isolamento/ } \\
\text { fontes de infecção }\end{array}$} & \multicolumn{7}{|c|}{ Listeria monocytogenes } & \multirow{2}{*}{$\frac{\text { L. ivanovii }}{5}$} & \multicolumn{2}{|c|}{ L. innocua } & \multirow[t]{2}{*}{ L. grayi } & \multicolumn{2}{|c|}{ Total } \\
\hline & $1 \mathrm{a}$ & $1 \mathrm{~b}$ & $3 a$ & $4 a$ & $4 a b$ & $4 b$ & $4 \mathrm{e}$ & & $6 a$ & $\mathrm{Nt}^{*}$ & & No & $\%$ \\
\hline \multicolumn{14}{|l|}{ Sistema nervoso central/ } \\
\hline Bovino & - & 1 & - & - & - & 6 & - & - & - & - & - & 7 & 2,8 \\
\hline Caprino & - & - & - & - & - & 3 & - & - & - & - & - & 3 & 1,2 \\
\hline Ovino & - & - & - & - & - & 2 & - & - & 1 & - & - & 3 & 1,2 \\
\hline Canino & 1 & - & - & - & - & - & - & - & - & - & - & 1 & 0,4 \\
\hline Roedor & - & 1 & - & - & - & - & - & - & - & - & - & 1 & 0,4 \\
\hline Fígado/bovino & 2 & - & - & - & - & 1 & - & - & - & - & - & 3 & 1,2 \\
\hline Fezes/bovino normal & 1 & 8 & 1 & 37 & 5 & 22 & 1 & 1 & 96 & 44 & - & 216 & 87,8 \\
\hline Conteúdo estomacal- & & & & & & & & & & & & & \\
\hline vísceras/feto bovino & - & 2 & - & - & - & - & 1 & - & 1 & - & - & 4 & 1,6 \\
\hline Secreções/ & & & & & & & & & & & & & \\
\hline auricular/canino & 1 & - & - & - & - & - & - & - & - & - & - & 1 & 0,4 \\
\hline Nasal/bovino normal & - & - & - & - & - & - & - & - & - & - & 1 & 1 & 0,4 \\
\hline $\begin{array}{l}\text { Vísceras sangue/ } \\
\text { roedor (chinchila) }\end{array}$ & 4 & - & - & - & - & 2 & - & - & - & - & - & 6 & 24 \\
\hline Total & 9 & 12 & 1 & 37 & 5 & 36 & 2 & 1 & 98 & 44 & 1 & 246 & 99,8 \\
\hline
\end{tabular}

Outro ponto que merece ser destacado refere-se ao predomínio das amostras oriundas de bovinos, totalizando $231(93,9 \%)$, sendo que $217(88,2 \%)$ originaram-se de animais sadios, em contraposição à discreta casuística daqueles portadores de alguma patologia (14/5,6\%). Nas demais espécies animais (roedores, caprinos, ovinos e caninos) apresentando sinais clínicos variados, ficaram limitados a um número exíguo $(15 / 6,0 \%)$ do universo de amostras de Listeria analisadas (Quadro 1).

Do ponto de vista da origem geográfica, foi patente a prevalência das amostras do estado do Rio de Janeiro $(231 / 93,9 \%)$ sobre as demais proveniências: Rio Grande do Sul $(12 / 4,4 \%)$ e Pernambuco $(3 / 1,2 \%)$.

Quanto à distribuição das espécies de Listeria (Quadros 2 e 3), foi notória a predominância de Listeria innocua sorovar 6a e não tipável (142/57,6\%), resultantes principalmente de fezes de bovinos normais do estado do Rio de Janeiro e tendo, em segundo plano, L. monocytogenes com 102 amostras $(41,4 \%)$, das quais $75(30,4 \%)$ oriundas de bovinos normais, também do estado do Rio de Janeiro.

Com menor expressão, cita-se a detecção de L. ivanovii e $L$. grayi, em bovinos hígidos, com os isolamentos obtidos a partir de fezes e secreção nasal, respectivamente.

Em relação aos processos patológicos (Quadro 3) salienta-se que, na maioria das vezes, foram definidos apenas pela referência da fonte de isolamento, tendo em vista que os protocolos anexados nas amostras remetidas raramente continham um histórico dos sinais clínicos, quando muito, constando de expressões como: suspeito de raiva, de encefalite, de septicemia, etc.

Os resultados obtidos categorizam as localizações preferenciais de L. monocytogenes (Quadro 3), concentradas no sistema nervoso central de ruminantes ( 12 casos, $4,8 \%$ ). Eletivamente, o sorovar $4 \mathrm{~b}$ apresentou este sítio em 11 casos, embora nos conteúdos estomacais de fetos bovinos e de fígado de adultos do Rio Grande do Sul os sorovares foram distintos (1a, 4b e 4e).

Considerando ainda a freqüência dos sorovares de $L$. monocytogenes, verifica-se (Quadro 3) que o tipo 4a foi o mais destacado (37/15,0\%), embora detectado apenas em fezes de bovinos normais, enquanto que o sorovar $4 \mathrm{~b}$, dos 36 isolados $(14,6 \%), 22$ (8,9\%) originaram-se de fezes de bovinos hígidos e 14 (5,6\%) de animais doentes de diversas espécies. Em contraposição, no grupo sorológico 1 (1a e 1b), das 21 amostras 12 (4,8\%) provieram de animais doentes e $9(3,6 \%)$ de indivíduos normais. Destaca-se o maior envolvimento do sorovar 1a com 8 isolados $(3,2 \%)$ de animais, particularmente os roedores, com alguma patologia ou sinal clínico.

\section{DISCUSSÃO}

Desde o seu reconhecimento oficial a 77 anos (Murray et al. 1926) como agente etiológico de doença em animais, e no homem até algum tempo passado, o isolamento de Listeria monocytogenes era considerado um acontecimento excepcional. Esta idéia se manteve arraigada de tal forma que incutiu na maioria dos profissionais o conceito de uma doença rara (Hofer 1974).

A partir de 1960, observou-se um número crescente de isolamentos em diferentes espécies de animais (Gray \& Killinger 1966), acentuando-se ainda mais nas duas últimas décadas do século passado, inclusive com a ocorrência no homem sob a forma de surtos transmitidos por alimentos (Hofer 2001). Aliás, esta situação veio corroborar com a opinião de Pirie (1927), de que $L$. monocytogenes era predominantemente veiculada por alimentos, tanto para o homem como animais.

Curiosamente, esta ampla distribuição de Listeria no reino animal apresenta um paradoxo diante de sua ocorrência esporádica como doença. A suposição seria de uma frequiência muito mais compatível com a sua ampla disseminação na natureza. Por sinal, esta situação está bem retratada no Quadro 3, quando se observa que no universo de 246 amostras analisadas, apenas 29 $(11,7 \%)$ tinham uma associação com um quadro patológico e 
sempre definidas com $L$. monocytogenes, enquanto 217 outras $(88,2 \%)$ se originaram de bovinos aparentemente normais (Hofer 1983). É óbvio que neste cômputo outras espécies de Listeria estavam presentes, com realce para $L$. innocua $(142 / 57,6 \%)$, embora seja necessário destacar as 75 cepas $(30,4 \%)$ de $L$. monocytogenes isoladas, principalmente de bovinos normais.

Coadunando-se com a presente investigação, salienta-se que na bibliografia nacional sobre a listeriose animal predominaram os relatos em ruminantes desde a curiosa nota de Maroja et al. (1962) no Pará. Os autores realizavam uma pesquisa sobre pasteurelose, quando registraram o isolamento de Listeria em três bovinos, a partir de hemoculturas que foram mantidas a $37^{\circ} \mathrm{C}$ por cinco meses. Em sequiência, Fernandes et al. (1971) descreveram a forma encefálica da listeriose em ovino, realizando com êxito a reprodução da doença em ovelhas, inoculadas por via suboccipital com a amostra recém isolada. Ainda nesta mesma época (Hofer 1971, 1972) detectou L. monocytogenes sorovar $4 \mathrm{~b}$ de material encefálico de bovino com sintomatologia compatível de encefalite rábica, além de notificar o isolamento de L. grayi de secreção nasal de bovino normal.

Outras observações sobre o binômio Listeria-listeriose em bovinos foram realizadas em décadas posteriores como a de Freitas et al. (1982) que descreveram o andar em círculo de um animal com abscesso cerebral; Hofer (1983) investigando a incidência de portadores fecais em bovinos aparentemente sadios; Santos et al. (1984) evidenciando a encefalite listeriótica em bezerros, apresentando sintomas neuro-paralíticos, e mais recentemente Sanchez et al. (2000), com base em um estudo anátomopatológico retrospectivo de 36 anos, assinalaram três casos de meningoencefalite bulbar com micro-abscessos nos 305 bovinos analisados, sem o isolamento da bactéria.

Do ponto de vista epidemiológico, com implicações ecológicas nas infecções por Listeria nos ruminantes, aponta-se a maior tendência de portadores entre os animais herbívoros, excretando pelas fezes a bactéria (Kampelmacher \& van Noorle Jansen 1969, Skovgaard \& Morgan 1988, Husu 1990), fato observado por Hofer $(1974,1983)$ em fezes de bovinos normais abatidos em matadouro. Aliado à presença de portadores de Listeria e a sua eliminação para o meio ambiente, salienta-se a capacidade de sobrevivência desta bactéria por períodos variáveis em solos de diferentes qualificações (Lehnert 1960; Welshimer 1968, Hofer \& Póvoa 1984), que favorecem a contaminação externa de vegetais (Weis 1975, Hofer 1975b) e alimentos ensilados (Gray \& Killinger 1966, Skovgaard \& Morgan 1988).

Um outro aspecto, até certo ponto inusitado na esfera patológica, refere-se aos isolamentos de $L$. innocua sorovar 6a de material do sistema nervoso central de um ovino (Rio de Janeiro) e do conteúdo estomacal de feto bovino (Rio Grande do Sul) Quadro 3. Na literatura se tem o respaldo de Walker et al. (1994), que detectaram esta espécie em um ovino com discreta encefalopatia decorrente de meningoencefalite.

Quanto à patogênese da infecção fetal é reconhecida a importância da disseminação hematogênica até a placenta, segundo as observações realizadas em ovinos por Njoku et al. (1972). Associando-se esta particularidade com o elevado número de portadores fecais nos ruminantes de espécies de Listeria, em especial L. innocua (Hofer 1983, Skovgaard \& Morgan 1988) é pos- sível suscitar a hipótese da disseminação hematogênica com localizações extra-intestinais, mesmo de membros considerados apatogênicos. Obviamente, tais situações são mais favorecidas nos indivíduos imunocomprometidos, como durante a gestação e nos recém-natos, bem como sob intervenção de terapias imunossupressivas, como o uso de glicocorticóides, que produzem a linfocitopenia, em particular dos linfócitos T, implicando na disseminação ou paralisação da atividade fagocitária dos macrófagos (Tripathy \& Mackaness 1969).

Em relação aos sorovares de $L$. monocytogenes identificados nos ruminantes com processos patológicos no sistema nervoso central, predominou o sorogrupo $4 \mathrm{~b}$, enquanto nas localizações hepáticas e nos materiais fetais os sorovares $1 \mathrm{~b}$ e $1 \mathrm{a}$ foram os mais incidentes e oriundos exclusivamente do Rio Grande do Sul. Em contraposição, nas fezes de bovinos destaca-se a amplitude do painel de sorovares, tendo como um dos mais frequientes o tipo 4b e a ocorrência bem mais discreta do sorogrupo 1 (1a e $1 \mathrm{~b})$.

Nos animais monogástricos, representados pelos roedores incluindo chinchilas e em menor escala os caninos, o acontecimento da listeriose foi bem mais raro (Quadro 3). Todavia, como em outras partes do mundo, provavelmente a primeira referência de isolamento de Listeria em nosso meio também foi em roedor silvestre do nordeste do país, a partir de cultivos de fígado e baço (Macchiavello 1942). Na ocasião o autor realizava na área uma prospecção bacteriológica da peste murina (Yersinia pestis). Posteriormente, Pacheco \& Dias (1956) apontaram a Listeria monocytogenes como responsável por um quadro de oftalmia em coelhos de biotério. A listeriose canina em nosso meio ficou restrita a observação de Freitas et al. (1990), que isolaram Listeria monocytogenes sorovar $1 \mathrm{~b}$ de um animal apresentando sintomas neuroparalíticos, similares aos da raiva e outra de secreção auricular, sorovar 1a (dados não publicados).

No caso presente, os isolados dessas fontes de infecção foram bem mais reduzidos do que aqueles dos ruminantes, mas com a particularidade do predomínio do sorovar 1a e com as localizações anatômicas fora da esfera do sistema nervoso central, compatibilizando-se com as citações de outros autores (Low \& Donachie 1997).

Em síntese, os membros do gênero Listeria têm uma ampla distribuição de fontes de infecção, além de apresentarem uma certa resistência as condições impostas pelo meio ambiente, possibilitando a sua sobrevivência e veiculação para novos hospedeiros. Esta fase retrata o ciclo de uma sapronose ou da participação hidro-telúrica (Hofer 1974) e que, em determinadas situações, poderá evoluir até a veiculação direta e/ou indireta da bactéria de fontes animais para o homem, caracterizando-se como uma zoonose (Hofer 1974).

Agradecimentos.- A todos os colegas e instituições que colaboraram com o envio de amostras. Aos técnicos Rosemary Ribeiro, Deise Paranhos Feitosa (in memoriam) e Evaldo Soares da Silva, do Departamento de Bacteriologia do Instituto Oswaldo Cruz, pelo apoio ao longo do trabalho.

\section{REFERÊNCIAS}

Farber J.M. \& Peterkin P.I. 1991. Listeria monocytogenes, a food-borne pathogen. Microbiol. Rev. 55:476-511. 
Fernandes J.C.T., Bollwann W. \& Siqueira C.S. 1971. Listeriose em ovinos no Rio Grande do Sul: descrição de um caso. Revta Med. Vet. 7:131-137.

Freitas M.A.Q., Santos J.A., Magalhães H. \& Carv1alho E.C.Q. 1982. Abscesso cerebral por Listeria monocytogenes em bovino. Pesq. Agropec. Bras. 17:137-141.

Freitas M.A.Q., Romijn P.C. \& Magalhães H. 1990. Listeriose encefálica em cão. Revta Bras. Med. Vet. 12:23-24.

Gray M.L. \& Killinger A.H. 1966. Listeria monocytogenes and listeric infections. Bacteriol. Rev. 30:309-382.

Hofer E. 1971. Presença de Listeria monocytogenes em material encefálico de bovino. Arqs Inst. Biológico, São Paulo, 38:285-287.

Hofer E. 1972. Studies on a strain of Listeria (L. grayi) isolated from bovine nasal secretion. Revta Microbiol., São Paulo, 3:101-102.

Hofer E. 1974. Contribuição ao estudo epidemiológico da ocorrência de portadores de Listeria monocytogenes entre operários de matadouro e indivíduos com distúrbio entéricos. Tese de Livre Docência, Instituto de Veterinária, Universidade Federal Rural do Rio de Janeiro, Seropédica, RJ. $114 \mathrm{p}$.

Hofer E. 1975a. Isolamento e caracterização de Listeria monnocytogenes em água de esgoto. Mem. Inst. Oswaldo Cruz 73:31-38.

Hofer E. 1975b. Study on Listeria spp on vegetable suitable for human consumption. VIII Congr. Bras. Microbiologia, Salvador, BA, p.21. (Resumo)

Hofer E. 1983. Bacteriologic and epidemiologic studies on the occurrence of Listeria monocytogenes in healthy cattle. Zbl. Bakteriol. Hyg. A 256:175283.

Hofer E. \& Póvoa M.M. 1984. Pesquisa de Listeria monocytogenes em solos. Mem. Inst. Oswaldo Cruz 79:45-93.

Hofer E. 2001. Três decênios de experiência sobre Listeria no Brasil, p.111115. In: Mercadante A.Z., Bobbio P.A., Bobbio J.L., Pereira J.L. \& Pastore G.M. (ed.) Ciência de Alimentos: Avanços e Perspectivas. Faculdade de Engenharia de Alimentos, Unicamp, Campinas, SP.

Husu J.R. 1990. Epidemiological studies on the occurrence of Listeria monocytogenes in the faeces of dairy cattle. J. Vet. Med. B 37:276-282.

Kampelmacher E.H. \& van Noorle Jansen L.M. 1969. Isolation of Listeria monocytogenes from feces of clinically healthy humans and animals. $\mathrm{Zbl}$. Bakteriol. Hyg., Abt.1, 221:353-359.

Lehnert C. 1960. Die Tenazität von Listeria monocytogenes in der Aussenwelt Zbl. Bakteriol., Abt.1, 180:350-356.

Low J.C. \& Donachie W. 1997. A review of Listeria monocytogenes and Listeriosis. Vet. J. 153:9-29.

Macchiavello A. 1942. Estudo de una cepa de Listeria monocytogenes aislada de rata. Arqs Hig. Saúde Pública 12:105-108.
Maroja O.M., Abreu A.C.V.V. \& Mendonça W.B. 1962. Encontro de um organismo identificado com Listeria monocytogenes em bovinos do Pará. Revta Serv. Esp. Saúde Pública 12:179-184.

Murray E.G.D., Webb R.A. \& Swann M.B.R. 1926. A disease of rabbbits characterized by a large mononuclear leucocytosis caused by a hitherto undescribed bacillus, Bacterium monocytogenes. J. Pathol. Bacteriol. 29:407439.

Njoku C.O., Dennis S.M. \& Cooper R.F. 1972. Listeric abortion studies in sheep. I. Materno-fetal changes. Cornell Vet. 62:608-627.

Pacheco G. \& Dias V.M. 1956. Oftalmia listeriosa em coelhos. Bolm Soc. Bras. Med. Vet. 24:15-24.

Pirie J.H.H. 1927. A new disease of veld rodents, "Tiger River Disease". South African Inst. Med. Res. Publ. 3:163-186.

Pirie J.H.H. 1940. Listeria: Change name for a genus bacteria. Nature 145:264.

Rocourt J., Schrettenbrunner A. \& Seeliger H.P.R. 1983. Differenciation biochimique des groupes genomiques de Listeria monocytogenes (sensu lato). Ann. Inst. Pasteur Microbiol. 134 A:65-71.

Sanches A.W.D., Langohr I.M., Stigger A.L. \& Barros C.S.L. 2000. Doenças do sistema nervoso central em bovinos no sul do Brasil. Pesq.Vet. Bras. 20:113-118.

Santos J.A., Freitas M.A.Q., Magalhães H. \& Ribeiro A.G.P. 1984. Listeriose encefálica em bezerros. Pesq. Agropec. Bras. 19:95-100.

Seeliger H.P.R. 1961. Listeriosis. 2nd ed. Hafner Publishing Co., New York. 308p.

Seeliger H.P.R. \& Höhne K. 1979. Serotyping of Listeria monocytogenes and related species, p.31-49. In: Bergan T \& Norris J.R. (ed.) Methods in Microbiology. Vol. 13. Academic Press, London.

Skovgaard N.S. \& Morgan C.A. 1988. Detection of Listeria spp. in faeces from animals, in feeds, and in raw foods of animal origin. Int. J. Food Microbiol. 6:229-242.

Tripathy S.P. \& Mackaness G.B. 1969. The effect of cytotoxic agents on the primary response to Listeria monocytogenes. J. Exp. Med. 130:1-16.

Walker J.K., Morgan J.H., Mc Lauchin J., Grant K.A. \& Schallcross J.A. 1994. Listeria innocua isolated from a case of ovine meningoencephalitis. Vet. Microbiol. 42:245-253.

Watkins J. \& Sleath K.P. 1981. Isolation and enumeration of $L$. monocytogenes from sewage sludge, and river water. J. Appl. Bacteriol. 50:1-9.

Weis J. 1975. The incidence of Listeria monocytogenes on plants and in soil, p.61-65. In: Problems of Listeriosis. Proc. 6th Int. Symposium, Leicester University Press, Leicester.

Welshimer H.J. 1968. Isolation of Listeria monocytogenes from vegetation. J. Bacteriol. 95:300-303. 